\title{
Landscape Pattern Evolvement in Mining Area: a Case of Liyuan Town in China
}

\author{
Zeng Hui ${ }^{\mathrm{a}}$, Zhou Jinhua ${ }^{\mathrm{b}}$ \\ ${ }^{a}$ China Woman's University, School of Sociology and Law Beijing, Beijing, China \\ ${ }^{b}$ China Coal Research Institute, Tangshan Branch, Tangshan, China
}

\begin{abstract}
Landscape pattern in mining area is both the result of long-term action of multi driving forces and the base of regional coordination and development. This paper takes Liyuan Town, where Jinggezhuang locates, in Tangshan as an example and analyzes land use changes in the year 1997 and 2003 using GIS. The results showed that in mining area in urban-rural fringe of plain area, the number and the fragmentation of the patches increased and the patch density as the whole was in a rising trend. And the patch number of each type of landscape distributed unevenly. The landscape pattern characteristics and evolvement in Liyuan Town indicates that under the double functions of mining development and urbanization, it is necessary adequately to obey the evolvement regularity of special landscape in region to promote the evolvement of landscape destruction, restoration, reconstruction and function, in order to realize the regional coordination development.
\end{abstract}

Index Terms: Urban-Rural Fringe; Landscape Pattern; Jinggezhuang Mine; Tangshan City

(C) 2011 Published by MECS Publisher. Selection and/or peer review under responsibility of the International Conference on E-Business System and Education Technology

\section{Introduction}

The region is both the matrix and the carrier in mining area. In a certain area, the mining landscape pattern forms under the impact of mining. However, due to the long-term mining disturbance, the negative external impact has spread over the whole region, which decreases the regional security of land use. Facing the rapid industrialization and urbanization, with the aim to ease the pressure of land resource restriction, it is obvious to start with the land use pattern first to obey the regularity of natural evolvement and further to realize the regional harmonious development. This paper takes Liyuan Town, where Jinggezhuang Mine locates, as a case and analyzes the change characteristics of the regional landscape pattern and the mining land landscape pattern. And then it is to obtain the background values of the landscape pattern in mining area to reveal the regional the evolvement regularity of regional landscape pattern, which lays the foundation for the sustainable development in mining area.

Corresponding author:

E-mail address: ${ }^{a}$ zenghuibj@163.com 


\section{Research Method}

The research method in this paper is to establish the landscape ecology data in different periods based on the remote sensing images and the present land-use maps and then to analyze landscape ecology with the support of GIS. The specific method is to take the changes of the cultivated land, the garden and forest land, the settlement and industrial land, the water land, the road land and the unused land as the objects and the land-use data in 1997 and the remote sensing image SPOT as data sources, and then to lead the processed land-use data into the GIS, and thirdly to establish the distribution pattern of different landscapes in 1997 and 2003 respectively by the space analysis function of GIS, and finally to calculate all the landscape indexes through the soft FRAGSTATS3.3 [1-4].

\section{Land-use landscape structures}

\subsection{Land-use landscape structures in 1997}

Of the land-use structures in 1997, the cultivated land accounted for 50.97\%, in a dominant position for the regional land use, which was as the matrix of all landscapes; the settlement and industrial land accounted for $24.67 \%$, clustered shape; the unused land accounted for $9.25 \%$, in the fragmented distribution, mainly composed of the gulch and the pond; the water land accounted for $7.27 \%$, mainly composed of the subsided seeper and the pound; the road land and the garden and forest land accounted for $4.20 \%$ and $3.60 \%$ respectively (Fig. 1).

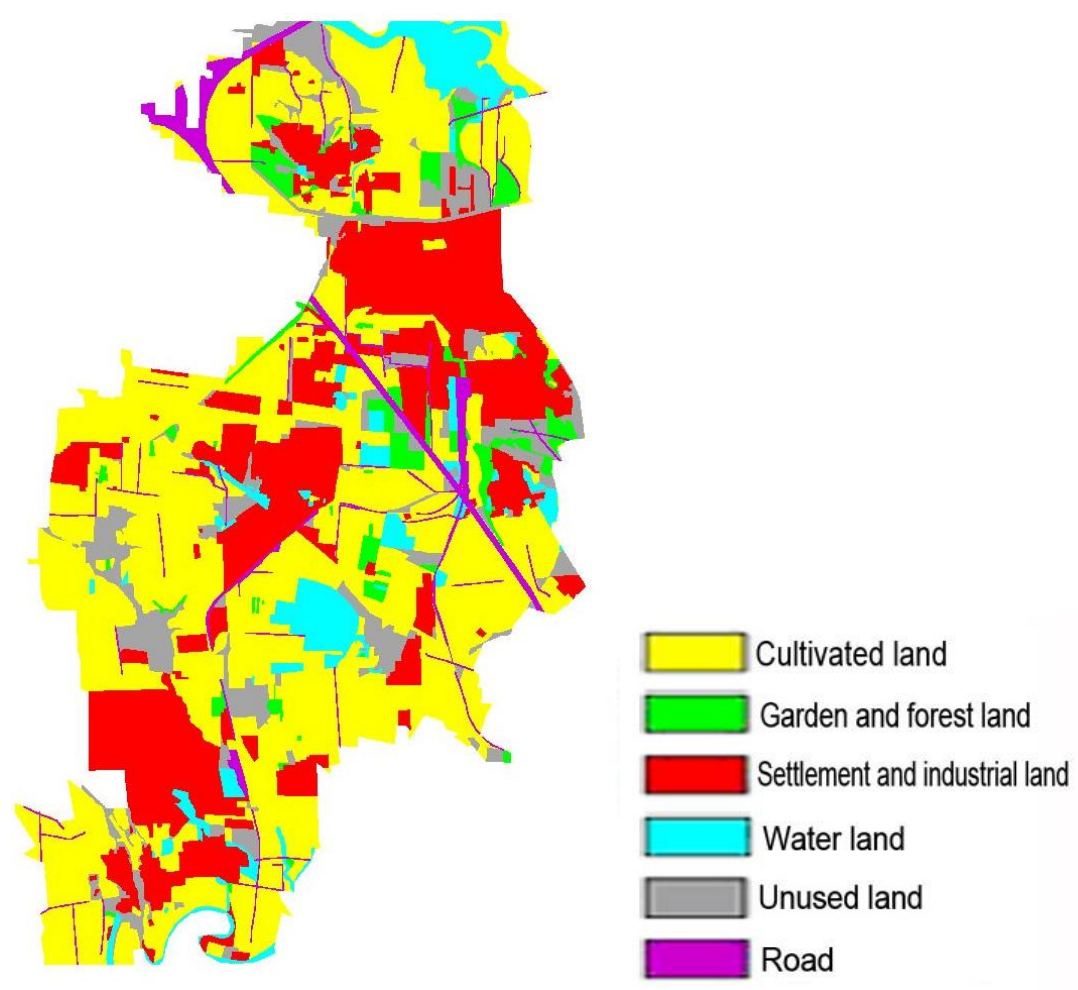

Fig. 1. Landscape distribution in 1997 


\subsection{Land-use landscape structures in 2003}

Of the land-use structures in 2003, the cultivated land accounted for $46.40 \%, 4.57 \%$ less than that in 1997 , still in a dominant position for the regional land use; the settlement and industrial land accounted for $26.16 \%$, $1.49 \%$ more than that in 1997; the water land accounted for $8.80 \%$ in the third place, more than the unused land, and the water land increased $1.53 \%$ mainly because of the increasing area of the subsided seeper; the area of the unused land decreased $2.36 \%$ than that in 1997; the area of the garden and forest land increased $3.50 \%$ (Fig.2).

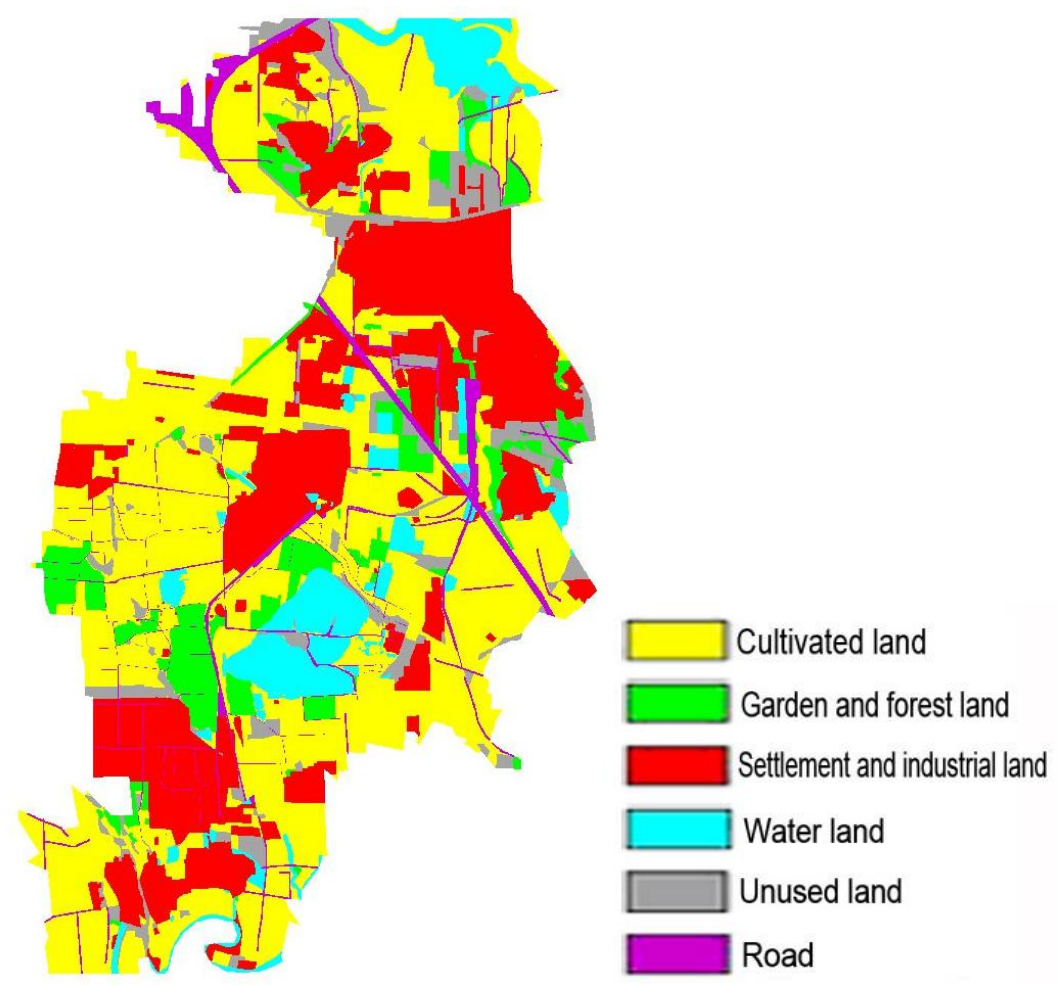

Fig. 2. Landscape distribution in 2003

The data from 1997 to 2003 in Table 1 indicate that: the area of the garden and forest land grew the fastest with the change rate $3.50 \%$ and the annual change rate $0.58 \%$, while the area of cultivated land decreased the fastest with the annual change rate $0.76 \%$, which indicated that in this period the structures of the regional agricultural land changed because of the structural adjustment of agricultural land; the area of the unused land decreased $0.39 \%$ per year, and that of the water land increased $0.26 \%$ per year, which indicated that the area of subsided seeper caused by mining expanded and land reclamation improved the land utilization ratio.

Table 1. Landscape Structure Changes From 1997 To 2003

\begin{tabular}{ccccccc}
\hline \multicolumn{1}{c}{ Index } & $\begin{array}{c}\text { Cultivated } \\
\text { land }\end{array}$ & $\begin{array}{c}\text { Garden and forest } \\
\text { land }\end{array}$ & $\begin{array}{c}\text { Settlement and industrial } \\
\text { land }\end{array}$ & $\begin{array}{c}\text { Water } \\
\text { land }\end{array}$ & $\begin{array}{c}\text { Unused } \\
\text { land }\end{array}$ & $\begin{array}{c}\text { Road } \\
\text { land }\end{array}$ \\
\hline Change area $/ \mathrm{hm}^{2}$ & -152.77 & 116.92 & 49.54 & 51.01 & -78.66 & 13.97 \\
Change rate/\% & -4.57 & 3.50 & 1.49 & 1.53 & -2.36 & 0.42 \\
\hline
\end{tabular}




\subsection{Landscape structure changes}

From 1997 to 2003, the landscapes with the most changing area are the cultivated land and the unused land. During that period, $278.25 \mathrm{hm}^{2}$ of the cultivated land (accounting for $16.32 \%$ of the total area of the cultivated land in 1997) changed, and $115.00 \mathrm{hm}^{2}$ of the unused land ((accounting for $37.20 \%$ of the total area of the unused grassland in 1997) changed. The cultivated land mainly converted to the garden and forest land, the settlement and industrial land and the water land. The unused land converted to the cultivated land and built-up land, $49.88 \mathrm{hm}^{2}$ of which was developed as the cultivated land for the compensation and $35.62 \mathrm{hm}^{2}$ as the built-up land. In terms of the landscape stability, the highest was the settlement and industrial land with the reserved rate above 90\%; the second were the garden and forest land and the water land with the reserved rate above $85 \%$; the third were the road land and the cultivated land with the reserved rate above $80 \%$.

\section{Patch characteristics}

\subsection{Patch size characteristics}

It is to obtain the number and the proportion of each type of landscape by GIS. The area information includes the total area, the proportion, the average value, the maximum value, the minimum value, the standard deviation. The perimeter information includes the total perimeter, the proportion, the average value, the maximum value, the minimum value, the standard deviation[3-5].

In 1997, the total number of the patches was 539 and the perimeter was $603 \mathrm{~km}$. In terms of the patch number, the patch numbers of all the landscapes distributed unevenly. The patch number of the cultivated land was the most, reaching 172, accounting for above 30\%; the following was the unused land, whose patch number was 119 , accounting for above $20 \%$ of the total patch number. There were some differences between the areas of all types of landscapes. The average area of the settlement and industrial land patches was the largest, $11.11 \mathrm{hm}^{2}$; the second was the cultivated land with the average area of $9.88 \mathrm{hm}^{2}$; the average area of the garden and forest land patches was the smallest, $2.00 \mathrm{hm}^{2}$. In terms of the change differences, the area of the cultivated land patches changed most, followed by the water land.

In terms of the total perimeter of the patches, the average perimeter of the road land patches was the longest, $1.93 \mathrm{~km}$; the following was the cultivated land with the average patch perimeter of $1.286 \mathrm{~km}$; the average perimeter of the settlement and industrial land patches was the smallest, only $0.27 \mathrm{~km}$.

In 2003 , the total number of patches was 1104 , and the total perimeter was $731.056 \mathrm{~km}$. Compared with those in 1997, the total number and the total perimeter both increased. In terms of the patch number of each type of landscape, the patch number of the cultivated land was still the most, reaching 570; the following were the unused land and road land, whose patch numbers were both near 150. Compared with the cultivated land in 1997, the number increased 400 more, which indicated that the cultivated land patches were further decentralized. Besides, the patch numbers of the road land and the unused land changed more, increasing 95 and 29 more respectively. And the others changed little. The differences between each type of landscape were further reduced. The average area of the water land patches was the largest, $10.02 \mathrm{hm}^{2}$, and that of the road land patches was the smallest, $1.07 \mathrm{hm}^{2}$.

In terms of the total perimeter of the patches, the average perimeter of the settlement and industrial land patches was the longest, $1.10 \mathrm{~km}$; the following was the road land with the average patch perimeter of $1.10 \mathrm{~km}$; the average perimeter of the cultivated land patches was the smallest, $0.45 \mathrm{~km}$. Compared with those in 1992 , the perimeter of the settlement and industrial land patches increased most and doubled; the following were the cultivated land patches and the road land patches, whose average perimeters reduced $0.8 \mathrm{~km}$. 


\subsection{Patch shape characteristics}

As to different types of land use patches, the graphical characteristics mean the patch shapes. Generally speaking, there is the positive correlation between the area and the perimeter of patches, that is that the larger the area, the longer the perimeter. However, in terms of the patches with the edge shapes of the different complexity, there is a big difference about the ratio of area and perimeter for different type of land use [6-8]. Through the soft FRAGSTATS3.3, it is to calculate the landscape indexes such as the ratio of perimeter and area, the fractal dimension and the shape index.

\section{(1) Perimeter/Area Ratio (PARA)}

In 1997, the landscape with the greatest PARA was the cultivated land; the following was the unused land; PARA of the settlement and industrial land was the smallest; the others' PARA had no obvious differences. It indicated that the shapes of the cultivated land and the unused land patches were more complex, while the shapes of the settlement and industrial land patches were more regular. In 2003, the landscape with the greatest PARA was still the cultivated land, followed by the road land, and PARA of the settlement and industrial land remained relatively small. Compared with PARA in 1997, PARA of all landscapes increased to different extent, the cultivated land and the road land with the great changes.

\section{(2) Fractal dimension (FRAC)}

In 1997, the landscape with the greatest FRAC was the road land; the following was the unused land; FRAC of the settlement and industrial land was the smallest. It indicated that the shapes of the road land and the unused land patches were the most complex, while the shapes of the settlement and industrial land patches were relatively regular. It showed the same regularity in 2003. Compared with FRAC in 1997, FRAC of the garden and forest land, the settlement and industrial land and the unused land increased, while the others' FRAC reduced.

\section{(3) Shape Index (SHAPE)}

In 1997, the landscape with the greatest SHAPE was the road land; the following was the unused land; SHAPE of the settlement and industrial land was the smallest. It indicated that the shapes of the settlement and industrial land patches approximated to the rectangle. In 2003, the landscape with the greatest SHAPE was still the road land, followed by the unused land, while SHAPE of the cultivated land was the smallest. Compared with SHAPE in 1997, SHAPE of all landscapes reduced to different extents, and the road land changed most. It indicated that the patch shapes of the road land patches and the water land patches were the most complex, and the shapes of the settlement and industrial land patches were the simplest; the shapes of the settlement and industrial land patches trended to the complexity, and the shapes of the road land patches trended to the simpleness.

\section{Landscape pattern characteristics}

\subsection{Dominance of landscape elements}

Landscape dominance is an index to measure the degree of the overall landscape controlled by one or a few elements of landscape. The greater the dominance of a type of landscape element is, the higher the degree of the overall landscape controlled by this landscape element; otherwise, if there is no any landscape element with the obvious dominance, it shows that there is the higher heterogeneity between the landscapes. And the relative density and the relative coverage of landscape elements are the considered firstly factors. 
Table 2. Landscape Dominance In Different Periods

\begin{tabular}{ccccccc}
\hline Year & $\begin{array}{c}\text { Cultivated } \\
\text { land }\end{array}$ & $\begin{array}{c}\text { Garden and forest } \\
\text { land }\end{array}$ & $\begin{array}{c}\text { Settlement and industrial } \\
\text { land }\end{array}$ & $\begin{array}{c}\text { Water } \\
\text { land }\end{array}$ & $\begin{array}{c}\text { Unused } \\
\text { land }\end{array}$ & $\begin{array}{c}\text { Road } \\
\text { land }\end{array}$ \\
\hline 1997 & 40.60 & 8.71 & 21.19 & 10.03 & 12.97 & 4.37 \\
2003 & 48.49 & 6.83 & 18.85 & 8.29 & 9.50 & 8.05 \\
\hline
\end{tabular}

In Table 2, the dominance of each landscape element in different periods indicated that the landscape dominance of the cultivated land in the urban-rural fringe was more obvious, and the dominance was in the rising trend with the process of the land reclamation project.

\subsection{Landscape fragmentation and diversity}

Landscape fragmentation is the process of landscape from the simpleness to complexity caused by the interference of natural or human factors. That is that the landscapes trend to be the complex, heterogeneous and discontinuous patch mosaics from the single, homogeneous and continuous whole [9]. Landscape fragmentation shows that the patch number increases while the patch area reduces, and the patch shape trends to be irregular, and the internal habitat area reduces, and the corridor is cut off, and the patch is separated from others.

The driving forces of the landscape fragmentation in mining area in the urban-rural fringe are mainly mining and urbanization. The matrix and patch are broken into the fragmentations continuously. And there is a close relationship between them with the interference intensity.

In 1997, the landscape with the greatest fragmentation was the garden and forest land, followed by the road land, while that of the cultivated land was the smallest. In 2003, the landscape with the greatest fragmentation was the unused land followed by the garden and forest land, and that of the cultivated land was still the smallest. From 1997 to 2003, the landscape fragmentations of the cultivated land, the settlement and industrial land and the unused land trended to increase, while others' trended to reduce. In the same period, the landscape diversity index increased from 1.35 to 1.43 , and the evenness index increased 0.05 , and the largest patch index decreased from 22.76 to 7.49 , which indicated that the landscape fragmentation caused by mining made the biodiversity increase and land reclamation, land consolidation and road construction enhanced the patch evenness.

\subsection{Patch density and edge density}

Patch density and edge density reflect the landscape integrity and fragmentation. The greater the patch density is, the more serious the landscape fragmentation is. On one hand, it reduces the area of a certain type of habitat and the area of each patch, which impacts the size and the extinction rate of species group; on the other hand, it impacts the spread and migration rates of species. Patch density refers to the patch number in the unit area of landscape. The greater the edge density is, the higher the degree of landscape types cut by the edge is; on the contrary, the landscape keeps the good connectivity.

In 1997, the landscape with the greatest patch density was the cultivated land, followed by the unused land, while that of the road land was the smallest. In 2003, the landscape with the greatest patch density was still the cultivated land, followed by road land, and that of the garden and forest land was smallest. From 1997 to 2003, the overall patch density was in the rising trend. The patch density of the cultivated land increased most, while that of the road land changed most.

In 1997, the landscape with the greatest edge density was the cultivated land, followed by the road land, while that of the garden and forest land was the smallest. In 2003, the landscape with the greatest edge density was still the cultivated land, still followed by the road land, and that of the water land was the smallest. From 1997 to 2003, the edge densities of all the landscapes except the unused land were in the rising trend. The edge density of the road land increased most and that of the road land still changed most followed by the cultivated 
land. To a certain extent the changes of patch density and edge density reflected that the landscape fragmentation changed acutely.

\subsection{Landscape contagion}

Landscape contagion refers to the non-randomness or the contagion degree of different types of landscapes. It reflects the adjacency relation and the mutual dispersity of a certain number of landscape types, which represents the adjacent heterogeneity of the patches.

In 1997, the landscape with the greatest contagion index was the settlement and industrial land, followed by the water land, while that of the road land was the smallest. In 2003, the landscape with the greatest contagion index was still the settlement and industrial land, followed by the water land, and that of the cultivated land declined, lower than that of the garden and forest land, and the unused land followed them, and that of the road land was still the smallest. In terms of the change trend, the contagion indexes of the garden and forest land and the water land were in the rising trend, while the others' were in decline.

\subsection{Barycenter evolvement of main landscapes}

Human activities must cause the changes of the regional landscape pattern. In order to manage the spatial change trend of the main landscapes, this paper is to describe the spatial development trend of all the landscapes by the barycenter evolvement, which provides reference for regional development planning. The moving distance of the barycenter shows the uneven degree of the spatial changes of the regional landscape quantity in a certain period. The longer the moving distance of the barycenter is, the greater the uneven degree of the spatial changes of the regional landscape quantity in a certain period is; on the contrary, the smaller the uneven degree is. The moving direction of the niche barycenter shows the source and the direction of the driving factors or forces of the spatial changes of regional landscapes.

It is to calculate the barycenter of all types of land by the following formulas:

$$
X_{i}=\frac{\sum_{j=1}^{n} x_{i j} * A_{i j}}{A}, Y_{i}=\frac{\sum_{j=1}^{n} y_{i j} * A_{i j}}{A}
$$

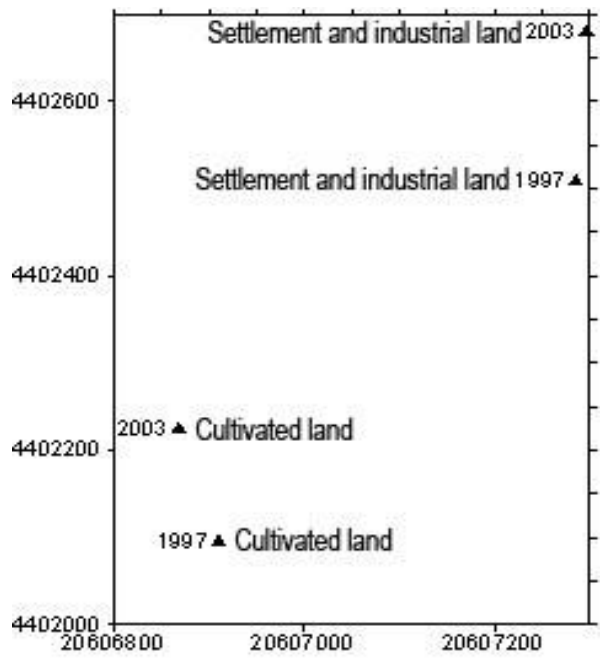

Fig. 3. Barycenter changes of the cultivated land and the settlement and industrial land 
Fig. 3 shows the barycenter of the cultivated land moved toward northwest $135 \mathrm{~m}$, mainly toward north from 1997 to 2003. The settlement and industrial land moved northeast $172 \mathrm{~m}$. On one hand, it shows Tangshan City is developing to the north; on the other hand, it shows the cultivated land in the north of Liyuan Town and the mining land in the northeast both increased because of the many years'treatment of Jinggezhuang Mine.

\section{Conclusion}

The development of mining city should coordinate with the regional development, and the integration of urban and rural areas should inherit the history. Therefore, disposing all the old to get new obviously does not accord with the scientific concept of development.Taking Liyuan Town, where Jinggezhuang locates, in Tangshan as an example, this paper studied the land pattern in 1997 and 2003, and then analyzed the characteristics of the regional landscape pattern changes and the landscape pattern of the mining land, and obtained the background values of the landscape pattern in the mining area, and then revealed the evolvement regularity of the regional landscape pattern, which lay a foundation for regional sustainable development.

(1) In 1997, the cultivated land was in the dominant position for the regional land use, as the matrix of all landscapes, and the settlement and industrial land showed the clustered shape, and the unused land was in the fragmented distribution; in 2003, the cultivated land was still in the dominant position, and the water land increased more, and the garden and forest land changed most, while the unused land was in the decreasing trend; the landscapes with the most changing area were the cultivated land and the unused land, and the landscape with the greatest stability was the settlement and industrial land.

(2) In 1997, the total patch number was 539, the patch number of each type of landscape distributed unevenly. The patch number of the cultivated land was the most, followed by the unused land; the average patch area of the settlement and industrial land was the most, followed by the cultivated land, and the smallest was the garden and forest land. In 2003, the total patch number was 1104, and the patch number of the cultivated land was still the most, followed by the unused land and the road land. The differences between the areas of all landscapes were decreasing, and the average patch area decreased, and the patch fragmentation increased.

The shapes of the road land and the water land were the most complex, while the structure of the settlement and industrial land was the simplest; the shapes of the settlement and industrial land patches trended to the complexity, and the shapes of the road land patches trended to the simpleness.

(3) The dominance of the cultivated land was obvious and in a rising trend; the fragmentation of the settlement and industrial land was the greatest, and the cultivated land, and the settlement and industrial land and the unused land trended to the fragmentation; the patch density as the whole was in a rising trend, the landscape with the most increase was the cultivated land, and the landscape with the most changes was the road land. The contagions of the garden and forest land and the water land were in the rising trend, while the others' were in the decreasing trend; the diversity and the evenness of the landscapes were in the rising trend, while the dominance was in a slight decrease, which indicated that the diversity was increasing; the barycenter of the cultivated land moved toward northwest $135 \mathrm{~m}$, and the settlement and industrial land moved northeast $172 \mathrm{~m}$. Their barycenters moved north.

\section{Acknowledgements}

This article is funded by National Scientific and Technical Supporting Programs during the 11th Five-year Plan (2006BAB15B06). The study is part of the project "Development of Safeguard and Control System of Land Resource in Different Functional Zones". 


\section{References}

[1] X. X.Yu, J. Z. Niu, W. B. Guan, et al, Landscape ecology. Beijing: Higher Education Press, 2006.(in chinese)

[2] J. P. Guo, Z. X. Zhou, Landscape ecology. Beijing: China Forestry Publishing House, 2007. (in chinese)

[3] B. J. Fu, L. X. Chen, K. M Ma, et al, Theory and Application of Landscape ecology. Beijing: Science Press, 2002. (in chinese)

[4] J. G. Wu, Landscape ecology — pattern, process, scale and hierarchy. Beijing: Higher Education Press, 2000. (in chinese)

[5] D. N. Xiao, Theory, method and application. Beijing: China Forestry Publishing House, 1991. (in chinese)

[6] H. Q. Xie, Research on LUCC based on multi-temporal remote sensing in coal mining area. Doctor Dissertation. China University of Mining and Technology (Beijing), 2005. (in chinese)

[7] H. B. Zhang, Research on ecological footprint changes in mining city based on GIS. Doctor Dissertation. China University of Mining and Technology (Beijing), 2007. (in chinese)

[8] F. P. Li, Study on the landscape ecology in abundant mines distract. Doctor Dissertation. University of Science and Technology Beijing, 2004. (in chinese)

[9] J. P. Guo, Forest Landscape Ecology. Beijing: Peking University Press, 2001. (in chinese) 